\title{
Clinical spectrum of AKI in chronic liver diseases
}

\author{
Purohit A. ${ }^{1 *}$, Pahawa N. ${ }^{2}$, Vohra R. ${ }^{3}$, Goswami S. ${ }^{4}$, Raju B. ${ }^{5}$, Malviya V. ${ }^{6}$, Shukla V. ${ }^{7}$, Parashar S. ${ }^{8}$, \\ Mishra A. ${ }^{9}$, Agrawal A. ${ }^{10}$ \\ DOI: https://doi.org/10.17511/ijmrr.2019.i02.05 \\ ${ }^{\text {1* }}$ Ashish Purohit, DM Resident, ${ }^{2}$ Naresh Pahawa, Professor, ${ }^{3}$ Rubina Vohra, Professor, ${ }^{4}$ S. Goswami, ${ }^{\mathbf{5}}$ Raju B., ${ }^{\mathbf{6}}$ V. Malviya, ${ }^{7}$ V. Shukla, ${ }^{8}$ \\ S. Parashar, ${ }^{9}$ A. Mishra, ${ }^{10}$ A. Agrawal; above all authors are attached with Department of Nephrology, Sri Aurobindo Medical College and \\ Postgraduate Institute, Indore, Madhya Pradesh, India.
}

Introduction: Acute kidney injury (AKI) is a heterogeneous syndrome of different aetiologies, and often multifactorial. Occurrence of Acute kidney injury in patients with chronic liver disease is frequent finding which makes prognosis of CLD even poorer. Material and methods: A prospective cohort observational study on 100 adult patients of chronic liver disease with AKI conducted over a period of 24 months from August 2016 to August 2018 at Sri Aurobindo medical college and postgraduate institute. Detailed clinical examination and biochemical tests were done. Univariate and multivariate logistic regression (odds ratio) analyses were used. Result: $87 \%$ are males and 13 $\%$ are females. The most common cause of cirrhosis is alcoholic $77 \%$ followed by hepatitis Bvirus related $10 \%$, unknown etiology $7 \%$, hepatitis C $3 \%$, NASH $2 \%$, Wilson 1 . The most common sign of decompensation of liver is jaundice $78 \%$ followed by ascites $70 \%$, hepatic encephalopathy $37 \%$ and upper GI bleed 30\%. Distribution of child class as a prognostic indicator showed the maximum no. ofpatients found in class C $56 \%$ followed by class B $34 \%$ and class A $10 \%$. Conclusion: Acute kidney injury is very common in chronic liver disease patient in our hospital and majority of them have intrinsic cause of AKI.

Keywords: Acute kidney injury, Chronic liver disease, Kidney function

Corresponding Author

Ashish Purohit, DM Resident, Department of Nephrology, Sri Aurobindo Medical College and Postgraduate Institute, Indore, Madhya Pradesh, India.
How to Cite this Article

To Browse

Purohit A, Pahawa N, Vohra R, Goswami S, Raju B, Malviya V, Shukla V, Parashar S, Mishra A, Agrawal A. Clinical spectrum of AKI in chronic liver diseases. Int J Med Res Rev. 2019;7(2):80-85. Available From

https://ijmrr.medresearch.in/index.php/ijmrr/article/ view/1040

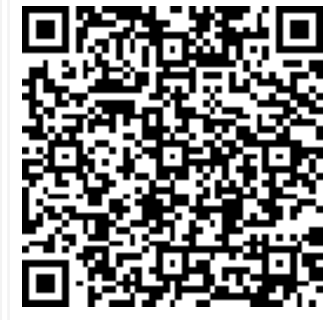

Manuscript Received 2019-03-30

Conflict of Interest No
Review Round 1 2019-04-08

Funding $\mathrm{Nil}$
Review Round 2 2019-04-16

Ethical Approval Yes
Review Round 3

Accepted 2019-04-20

Plagiarism X-checker $9 \%$

Note

(c) 2019 by Ashish Purohit, Naresh Pahawa, Rubina Vohra, S. Goswami, Raju B., V. Malviya, V. Shukla, S. Parashar, A. Mishra, A. Agrawal and Published by Siddharth Health Research and Social Welfare Society. This is an Open Access article licensed under a Creative Commons Attribution 4.0 International License https://creativecommons.org/licenses/by/4.0/ unported [CC BY 4.0]. 


\section{Introduction}

Incidence of AKI varies from $3 \%$ to $7 \%$ in hospitalized patient and $25 \%$ to $30 \%$ in intensive care unit (ICU) patient, approximately $5 \%$ to $6 \%$ patients who develop AKI, had to undergo dialysis. Chronic liver disease (CLD) is also a common clinical problem afflicting mankind. Its association with disease of other important organ kidney makes it a more devastating disease [1].

As AKI significantly impacts the outcome of patients with cirrhosis, it is important to prevent the development of AKI if possible and to identify the cause early enough so that appropriate treatment measures can be instituted $[2,3,4]$.

Occurrence of Acute kidney injury in patients with chronic liver disease is frequent finding which makes prognosis of CLD even poorer $[5,6]$. Physiological changes that occur in CLD place these patients at high risk for AKI [6]. Cirrhosis is an immunocompromised state, and these patients are at increased risk of infection [7]. Therefore, early evaluation and treatment of infection is imperative for patients with cirrhosis who develop an AKI [8].

\section{Material and Methods}

The present study is a hospital-based observational study conducted over a period of 24 months from August 2016 to August 2018 at Sri Aurobindo medical college and postgraduate institute, Indore. Consecutively admitted 100 adult patients of chronic liver disease with AKI were chosen for the study.

Study Design: Observational Study

\section{Inclusion Criteria}

01 . Age more than 18 years.

02. Diagnosed case of chronic liver disease.

03. Patient of acute kidney injury in chronic liver disease.

\section{Exclusion Criteria}

01. Known case of CKD.

02. Patients of chronic diseases such as active tuberculosis, malignancy.

Collection of data- Detailed clinical interview and physical examination were done at the time of admission. Clinical events (infection, AKI, bleeding, ascites, and encephalopathy) were carefully evaluated, then these patients were subjected to appropriate investigations.
During hospitalization complete hemogram, serum Total bilirubin, unconjugated bilirubin and conjugated bilirubin, serum total protein serum albumin, serum globulin, PT (Prothrombin time)/INR, alkaline phos-phatase, Blood urea (BU), serum creatinine $(\mathrm{sCr})$ at admission and daily till patient improve or discharge \& baseline report noted if available, serum electrolytes and ABG (arterial blood gas analysis) doneat admission and done whenever required, viral markers (HBsAg \& Anti HCV, HIV) were investigated.

Culture of ascitic fluid, blood, urine, and sputum were performed when an infection is suspected. Urine routine microscopy, urine electrolytes whenever relevant, ascitic fluid microscopy done when patients have ascites, Ultrasonography of Whole abdomen, chest $x$ ray, and the other lab investigation which were required for evaluation and treatment of patients.

The diagnosis of cirrhosis was based on clinical evaluation by a hepatologist using laboratory values, liver imaging, endoscopy, and (when available) liver biopsy [24]. Cirrhosis staged clinically by Child-Pugh classification (CPC) with scoring system of 5-15 score of 5 to 6 being CPC$\mathrm{A}, 7$ to 9 CPC-B and 10 to 15 being CPC $-\mathrm{C}$ [9].

Serum creatinine ( $\mathrm{sCr}$ ) measured at admission and daily till patient improve or discharge which ever earlier \& baseline report noted if available. During hospitalisation peak $\mathrm{sCr}$ value noted and compared with baseline sCr for staging of AKI.

Statistical analysis plan: Continuous variables were described as means ( $95 \%$ confidence interval) and the difference was observed by using $T$ test. ANOVA was carried out for $>2$ groups.

Differences for categorical variables were assessed by the chi-square test. Univariate and multivariate logistic regression (odds ratio $[\mathrm{OR}]$ ) analyses were used to identify those variables associated with AKI and mortality. pvalue $<0.05$ was considered significant.

\section{Results}

Table 1: Sex wise distribution of cases.

\begin{tabular}{|l|l|l|}
\hline \multicolumn{1}{|c|}{ S.No } & \multicolumn{1}{c|}{ Sex } & \multicolumn{1}{c|}{ No.of Patients } \\
\hline 1 & Female & 13 \\
\hline 2 & Male & 87 \\
\hline Total & 100 \\
\hline
\end{tabular}


Above table shows that males are predominant in our study than females i.e $87 \%$ are males and $13 \%$ are females.

\section{Table-2: Cause of Cirrhosis.}

\begin{tabular}{|l|l|l|}
\hline S.No. & \multicolumn{1}{|c|}{ Cause of cirrhosis } & \multicolumn{1}{c|}{ No. of patients } \\
\hline 1 & Unknown etiology & 7 \\
\hline 2 & Alcoholic cirrhosis & 77 \\
\hline 3 & Hepatitis B Virus related & 10 \\
\hline 4 & Hepatitis C Virus related & 3 \\
\hline 5 & NASH & 2 \\
\hline 6 & Willson's disease & 1 \\
\hline Total & & 100 \\
\hline
\end{tabular}

The most common cause of cirrhosis is alcoholic in $77 \%$ followed by hepatitits B virus related $10 \%$, unknown etiology $7 \%$, hep C $3 \%$, NASH $2 \%$, Wilson 1

Table-3: Decompensation of liver.

\begin{tabular}{|l|l|l|l|}
\hline $\begin{array}{c}\text { S. } \\
\text { No. }\end{array}$ & \multicolumn{1}{|c|}{ Complication } & \multicolumn{1}{|c|}{$\begin{array}{c}\text { No. of patients } \\
\text { Present }\end{array}$} & \multicolumn{1}{|c|}{$\begin{array}{c}\text { No. of patient } \\
\text { absent }\end{array}$} \\
\hline 1 & $\begin{array}{l}\text { Hepatic } \\
\text { encephalopathy }\end{array}$ & 37 & 63 \\
\hline 2 & Ascites & 70 & 30 \\
\hline 3 & Jaundice & 78 & 22 \\
\hline 4 & h/o UGI Bleed & 30 & 70 \\
\hline Total & 100 & 100 \\
\hline
\end{tabular}

The above table shows that the most common sign of decompensation of liver is jaundice $78 \%$ followed by ascites $70 \%$, hepatic encephalopathy $37 \%$ and upper GI bleed 30\%.

\section{Table-4: Distribution according to CHILD class}

\begin{tabular}{|l|l|l|}
\hline \multicolumn{1}{|c|}{ S. No. } & \multicolumn{1}{c|}{ CHILD Class } & \multicolumn{1}{c|}{ No. patients } \\
\hline 1 & A & 10 \\
\hline 2 & B & 34 \\
\hline 3 & C & 56 \\
\hline Total & 100 \\
\hline
\end{tabular}

Distribution of child class as a prognostic indicator as shown in above table the maximum no of patients found in class C $56 \%$ followed by class B $34 \%$ and class A $10 \%$.

Table-5: Stage of AKI

\begin{tabular}{|l|l|l|}
\hline \multicolumn{1}{|c|}{ S No. } & \multicolumn{1}{|c|}{ Stages of AKI } & \multicolumn{1}{c|}{ No. of Patients } \\
\hline 1 & AKI- 1 & 36 \\
\hline 2 & AKI-2 & 24 \\
\hline 3 & AKI-3 & 40 \\
\hline Total & 100 \\
\hline
\end{tabular}

Above table shows that maximum no. of patients found in AKI stage III $40 \%$ followed by stage I $36 \%$ then staqe II $24 \%$.
Table-6: Precipitating factors for AKI.

\begin{tabular}{|l|l|l|}
\hline S No. & \multicolumn{1}{|c|}{ Factors } & No. Of Patients \\
\hline 1 & Sepsis-CN1 & 33 \\
\hline 2 & Bacteraemia & 4 \\
\hline 3 & Candidiasis & 1 \\
\hline 4 & UTI & 8 \\
\hline 5 & Pneumonia & 4 \\
\hline 6 & SBP & 18 \\
\hline 7 & UGI Bleed & 10 \\
\hline 8 & Paracentesis & 4 \\
\hline 9 & Diarrhea & 4 \\
\hline 10 & Vomiting & 4 \\
\hline 11 & Diuretics & 9 \\
\hline 12 & Aminoglycosides (Amikacin) & 1 \\
\hline Total & & 100 \\
\hline
\end{tabular}

- Sepsis culture negative (blood, urine, ascitic fluid, sputum)

Above table shows the most common precipitating factor was sepsis $33 \%$ followed by SBP $18 \%$, UGI bleed $10 \%$, diuretics $9 \%$, UTI $8 \%$, paracentesis, Diarrhea, vomiting, bacteraemia, pneumonia $4 \%$ each, and aminoglycosides $1 \%$.

Table 7: Etiological classification of AKI with cirrhosis patients.

\begin{tabular}{|l|l|l|}
\hline S.No. & \multicolumn{1}{|c|}{ Classification } & \multicolumn{1}{c|}{ Number of patients } \\
\hline 1 & Pre-Renal & 28 \\
\hline 2 & HRS-AKI & 33 \\
\hline 3 & Intrinsic & 39 \\
\hline 4 & Other & 0 \\
\hline Total & 100 \\
\hline
\end{tabular}

Above study shows the etiological classification of AKI in cirrhosis patients in which the majority are of intrinsic AKI 39\% followed by HRS-AKI 33\% and pre renal AKI $28 \%$.

\section{Discussion}

This study is an observational hospital-based study. In this study we studied the clinical spectrum of AKI in cirrhosis patientsi.e. causes of AKI, precipitating factors for AKI in cirrhosis and the outcome of AKI in cirrhosis patients. In our study, out of 100 patients of cirrhosis with AKI, there are 87 males and 13 females, male to female ratio being 6.6: 1 . In several other studies males are more predominantly involved than females like Andrew $\mathrm{S}$ et al [10] found that Median (quartile1, quartile 3) age of the entire cohort was $58(50,65)$ years. The majority of participants were male $(71 \%)$, white race $(93 \%)$, and of non-Hispanic ethnicity $(87 \%)$. 
Jaiganesh at al [11] found mean age was $48.32 \pm$ 10.19 years. Of these, majority were male ( $95 \%$ $(95 / 100))$ and females were only 5\% (5/100).

Fleming $\mathrm{KM}$ et al [12] who also found an increased incidence of chronic liver disease with increase in age. This study showed that the majority of patients were male which is similar to our study. The study also found that the incidence was over $50 \%$ higher in men compared with women. In our study, alcoholic cirrhosis is the most common aetiology of cirrhosis that is $77 \%$ followed by hepatitis B (10\%) then hepatitis $\mathrm{C}(3 \%)$ then NASH $(2 \%)$ and then Wilson's disease $(1 \%)$.

Similarly Jaiprakash et al [13] found the Most common aetiology of cirrhosis was chronic alcoholism (29.8\%) followed by cryptogenic $(25.3 \%)$ and chronic hepatitis B (24.1\%). Other less common causes included chronic hepatitis $\mathrm{C}$ $(7.3 \%)$, primary biliary cirrhosis, non-alcoholic fatty liver disease, and autoimmune hepatitis, combined effects of alcoholism and hepatitis B, and Wilson's disease, in decreasing order of frequency.

Jaiganesh et al [11] found that, the most common aetiology of cirrhosis was alcohol $85 \%$ (85/100), followed by Hepatitis B $(11 \%(11 / 100))$ and $C$ virus $4 \%(4 / 100))$. Renal dysfunction was observed in $33.3 \%(5 / 15)$ of cirrhotic cases with viral aetiology. There is no significant association between the etiology of cirrhosis and renal disorders $(P=0.25)$. Of which 17 (20\%) alcohol related $5 \%$ of hepatitis B\&C develop AKI.

Quresi et al [14] found, Majority of the patients had their liver disease secondary to hepatitis $C$ with a mean MELD and Child-Pugh score of $17.4 \pm 4.6$ and $10 \pm 2$, respectively. Etiological finding of our study is similar to study done by Das et al [15] except with frequency, they found Alcohol, Hepatitis B, Hepatitis $C$ and non-alcoholic fatty liver disease (NAFLD) were among the causes of cirrhosis. Present study showed most common cause was alcohol followed by Hepatitis B and Hepatitis C.

Other studies done on cirrhosis patients also found alcohol was the most common cause of cirrhosis in Brij Sharma et al [16] alcohol in 62.9\%, HBV related $10.1 \%$ and $\mathrm{NASH}$ found in $<10 \%$ cases, in a study done by Apurva Shah et al[17] found alcohol in $48 \%, \mathrm{NASH}$ in $26 \% \mathrm{HBV}$ in $10 \% \mathrm{HCV}$ in $6 \%$ and $7 \%$ have others causes of cirrhosis. In present study the most common cause of cirrhosis is alcohol followed by HBV, HCV NASH, Wilson ds.
Which is similar to other studies, and in 7 cases aetiology of cirrhosis is unknown. Present study included 100 patients of cirrhosis with AKI admitted in our hospital, Number of cases in previous studies are as follows-

Kirk B et al [18] included 206 cirrhotic patients in which they studied renal dysfunction, Das et al [15] included 61 patients were admitted with chronic liver disease but among them 11 were not included in the study as they had existing kidney disease. Qun-Qun Jiang et al [19] studied 280 patients of cirrhosis with AKI. Jai Prakash et al [13] studied total of 404 cases of cirrhosis of liver inwhichOne hundred and seventyeight patients were diagnosed to have different forms of renal diseases.

Jaiganesh mohan et al [11] studied retrospectively reviewed medical records of 100 cirrhotic patients admitted in three month period. Kulkarni et al [20] studied 120 patients of cirrhosis of liver with acute kidney injury. In present study maximum AKI patients are found in Child Class C 56\%, in Child class B $34 \%$ and in Child class A $10 \%$ patients found it is similar to other study as Child class increases patients of cirrhosis have more incidence of AKI. similar to our study are-

Jaiprakash et al [13] proportionate increase in the incidence of renal disease with increase in the severity of liver disease as determined by ChildPugh classification. The incidence of renal diseases was $15.7 \%$ in class $A, 50 \%$ in class $B$, and $54.8 \%$ in class $\mathrm{C}$ of Child-Pugh classification.

These findings were also supported by Attia et al [21] found the incidence of renal disease was $6.7 \%$, $13.5 \%$, and $33.9 \%$ in patients with Child-Pugh class A, B, and C cirrhosis, respectively. Which also similar to present study.

Jaiganesh mohan et al [11] There is an increase in the number of renal disorder with increase in the severity of cirrhosis. In the cirrhotic patients with higher severity of cirrhosis (Child Pugh class B and $C)$, renal dysfunction was developed much more $(\mathrm{OR}=3.37 ; \mathrm{CI}=1.08-10.5 ; \mathrm{P}=0.03)$. This also similar to our study as the severity of liver disease increases no. of patients having renal dysfunction increases.

In present study hepatic encephalopathy were found in $37 \%$ cases, ascites in $70 \%$ cases, jaundice in $78 \%$ cases, H/O UGI bleed in $30 \%$ cases, Jaiganesh et al [11] found Among the renal dysfunction cases studied $45.5 \%$ (10/22) had hepatic encephalopathy 
Factor such as hepatic encephalopathy has been associated with the progression of AKI [22].

HRS is exclusively found in patients with cirrhosis with ascites, in our study 70 cases have ascites of which 33 cases i.e. 47.1\% (33/70) were found to have HRS-AKI. Which is contrary to our study, HRS1 affects about 7\% of hospitalised cirrhotic patients, both HRS1\&2 affecting approximately $10 \%$ of cirrhotic patients with ascites [22]. Precipitating factors of AKI in cirrhosis patients in our study were sepsis 33\%, SBP 18\%, upper GI bleed 10\%, diuretics $9 \%$, UTI $8 \%$, bacteremia $4 \%$, pneumonia $4 \%$, diarrhoea $4 \%$, vomiting $4 \%$, paracentesis $4 \%$, candidiasis $1 \%$, and aminoglycosides $1 \%$, in which the commonest cause is sepsis followed by SBP rest in decreasing order respectively.

There are many studies in which sepsis is one of the commonest cause of AKI in cirrhosis patients while rest of the other cause are in different orders similar finding also observe by Jaiprakash et al [13], in his study sepsis is the most common cause of AKI. So we conclude that AKI in cirrhosis is commonly due to Intrinsic AKI followed by HRS AKI \& pre renal AKI in decreasing order, and sepsis is most common precipitating factors for AKI. Others factors are Spontaneous Bacterial Peritonitis, Upper GastroIntestinal Bleed, Urinary Tract Infection, Diuretics use, diarrhoea, vomiting, and bacteraemia.

\section{Conclusion}

Acute kidney injury is very common in chronic liver disease patient in our hospital and majority of them have intrinsic cause of AKI. It is observed that frequency of renal disease keeps on increasing with increase in severity of liver disease.Further study and multicentre clinical trials are needed to help clinicians better diagnose andimprove outcomes in this critically ill group of patients.

\section{Reference}

01. Suk KT. Hepatic venous pressure gradientclinical use in chronic liver disease. Clin Mol Hepatol. 2014 Mar;20(1)6-14.

doi: 10.3350/cmh.2014.20.1.6 [Crossref]

02. Garcia-Tsao G, Parikh CR, Viola A. Acute kidney injury in cirrhosis. Hepatology. 2008 Dec;48(6)2064-77. doi: 10.1002/hep.22605 [Crossref]
03. Angeli $P$, Gines $P$, Wong $F$, et al. Diagnosis and management of acute kidney injury in patients with cirrhosis- revised consensus recommendations of the International Club of Ascites. Gut. 2015 Apr;64(4)531-7.

doi: 10.1136/gutjnl-2014-308874 [Crossref]

04. Garcia-Tsao G, Parikh CR, Viola A. Acute kidney injury in cirrhosis. Hepatology. 2008 Dec;48(6)2064-77. doi: 10.1002/hep.22605 [Crossref]

05. D’Amico G, Garcia-Tsao G, Pagliaro L. Natural history and prognostic indicators of survival in cirrhosis- a systematic review of 118 studies. J Hepatol. 2006;44;217-231. doi: 10.1016/j.jhep.2005.10.013 [Crossref]

06. du Cheyron D, Bouchet B, Parienti JJ, et al. The attributable mortality of acute renal failure in critically ill patients with liver cirrhosis. Intensive Care Med. 2005 Dec;31(12)1693-9. [Crossref]

07. Bonnel AR, Bunchorntavakul C, Reddy KR. Immune dysfunction and infections in patients with cirrhosis. Clin Gastroenterol Hepatol. 2011 Sep;9(9)727-38.

doi: $10.1016 /$ j.cgh.2011.02.031 [Crossref]

08. Fasolato S, Angeli P, Dallagnese $L$, et al. Renal failure and bacterial infections in patients with cirrhosis- epidemiology and clinical features. Hepatology. 2007 Jan;45(1)223-9. [Crossref]

09. Marc G. Ghany, Jay H. Hoofnagle (2015), Harrison's principles of internal medicine. New York- McGraw Hill Education.

19th ed- Vol 2, ch 357;1989-1995 [Crossref]

10. S Allegretti, Andrew, Ortíz, Guillermo, Wenger, Julia, Deferio et al. Prognosis of Acute Kidney Injury and Hepatorenal Syndrome in Patients with Cirrhosis- A Prospective Cohort Study. Int J Nephro. 2015;108139.

doi: $10.1155 / 2015 / 108139$ [Crossref]

11. Jaiganesh Mohan, et al. Clinical profile of renal dysfunction in cirrhotic liver. Int J Biomed Res. 2016;7(2)073-6.

DOI: $10.7439 /$ ijbr.CODEN:IJBRFA [Crossref] 
12. Fleming KM, Aithal GP, Solaymani-Dodaran M, et al. Incidence and prevalence of cirrhosis in the United Kingdom, 1992-2001- a general population-based study. J Hepatol. 2008 Nov;49(5)732-8.

doi: $10.1016 /$ j.jhep.2008.05.023 [Crossref]

13. Prakash J, Mahapatra A, Ghosh B, et al. Clinical Spectrum of Renal Disorders in Patients with Cirrhosis of Liver, Renal Failure. J Kidney diseases in cirrhotic patients. 2011 Jan; $33 ; 1 ; 40-46$.

DOI: 10.3109/ 0886 022X. 2010.541582 [Crossref]

14. Muhammad Omar Qureshi, Farzana Shafqat, Faisal Saud Dar, Mohammad Salih and Nasir Khokhar. 'Renal Failure in Patients with End Stage Liver Disease and its Impact on Clinical Outcome'. Journal of the College of Physicians and Surgeons Pakistan. 2014;24(9)628-631.

[Crossref]

15. Nupur Das, Agnihotri Bhattacharyya, Baishakhi Paria, and Sujoy Sarkar. "Study on Assessment of Renal Function in Chronic Liver Disease". J Clin Diagn Res. 2015 Mar;9(3)OC09-OC12.

doi: $10.7860 / J C D R / 2015 / 11423.5658$ [Crossref]

16. Brij Sharma, Rishab Marwah, Sujeet Raina, Neetu Sharma, Madan Kaushik, Satinder Singh Kaushal. A study on the etiology of cirrhosis of liver in adults living in the Hills of Himachal Pradesh, India. Tropical Gastroenterology. 2008. DOI: doi.org/10.7869/tg.317 [Article] [Crossref]

17. Apurva S, Shah, Deepak N, Amarapurkar. Natural History of cirrhosis of liver after First Decompensation- A Prospective Study In India. Journal of clinical and Experimental Hepatology. 2017;1-8.

[Crossref]
18. Kirk B Russ, Todd $M$ stevens and Ashwani $K$ Singal. Acute kidney injury in patients with Cirrhosis. Journal of Clinical and Translational Hepatology. 2015;3(3)195-204.

[Crossref]

19. Qun-Qun Jiang, Mei-Fang Han, Ke Ma, Guang Chen, Xiao-Yang Wan, Semvua Bukheti Kilonzo. Acute kidney injury in acute-on-chronic liver failure is different from in decompensated cirrhosis. World J Gastroenterol. 2018 Jun 7;24(21)2300-2310. doi: $10.3748 / w j g . v 24 . i 21.2300$ [Crossref]

20. Ashok Kulkarni, Amol \& Rao, PN \& Hussaini, Shaistam \& Reddy, Nageshwar. Clinical profile, precipitating factors \& in-hospital mortality of acute kidney injury in cirrhosis of liver. Journal of Clinical and Experimental Hepatology. 3(1)S94;2013.

doi: 10.1016/j.jceh.2013.02.236 [Crossref]

21. Attia KA, N'driYoman AT, Mahassadi AK. Impact of renal failure on survival of African patients with cirrhosis. Saudi JKidney Dis Transpl. 2008; 19(4)587-592.

[Crossref]

22. Andrew S Allegretti, Guillermo Ortiz, Julia Wenger, Joseph J, Deferio Joshua Wibecan, Sahir Kalim. Prognosis of Acute Kidney Injury and Hepatorenal Syndrome in Patients with Cirrhosis- A Prospective Cohort Study. International Journal of Nephrology. 2015. [Article] [Crossref] 